\title{
REPORTE TÉCNICO
}

Estudio genético sobre sustitución de especies en el comercio de pescados en México

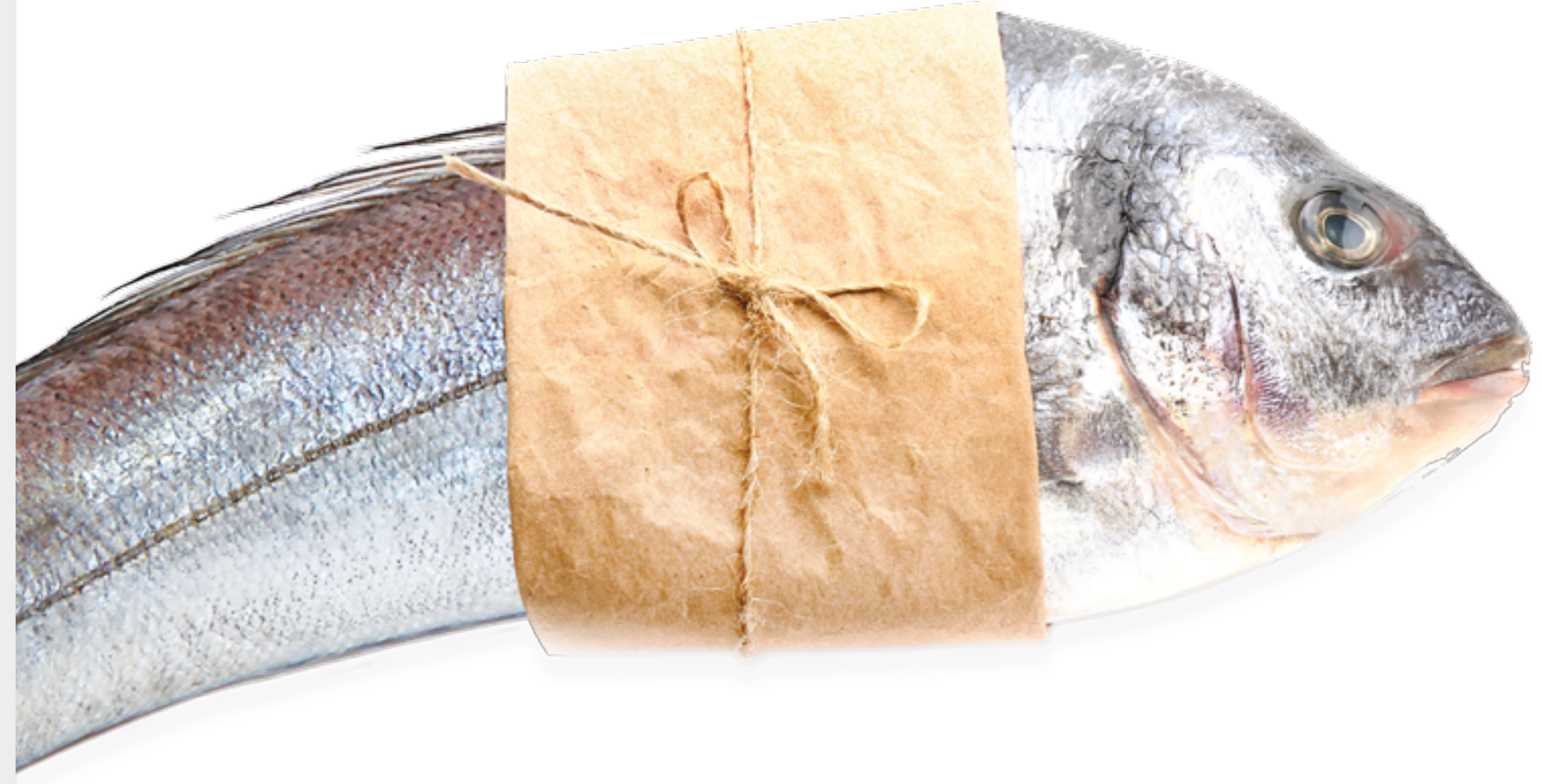

\section{OCEANA}




\section{REPORTE TÉCNICO}

Estudio genético sobre sustitución de especies en el comercio de pescados en México 


\section{INTRODUCCIÓN}

La sustitución de especies pesqueras (seafood mislabeling) ocurre cuando el nombrecientifico de una especie, por jemplo, identificadam od genética forense, no corresponde con el nombre comercial con el cual la muestra de pescado fue vendida. Dicha sustitución representa un obstáculo para el manejo sustentable y la comercialización de productos pesqueros, y contribuye a la pescailegal.

La sustitución de especies puede dar una percepción errónea acerca de la presencia y abundancia de especies comerciales que son populares entre los consumidores y que ocupan niveles tróficos superiores como depredadores, incluyendo pargos, meros, robalos, huachinangos, etc., que pueden ser sustituidos por

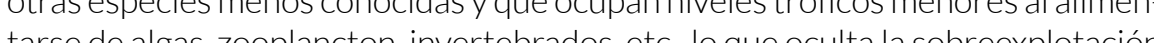

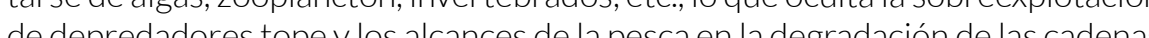
ecológicas de los ambientes marinos (Sala et al 2004). En consecuencia las especies que se emplean para sustituir a las más populares carecen de la atención de los tomadores de decisión y de un manejo adecuado a su nivel real de explotación. En este escenario, los pescadores que encuentran su sustento aprovechando especies poco conocidas se ven en la necesidad de aumentar sus capturas de bido al bajo precio que obtienen por estas, aun cuando sus productos pueden ser vendidos a altos precios al servir como sustitutos de especies comercialmente populares (Stawitz et al., 2017).

En otros casos, los consumidores pueden creer que están comprando o consumiendo un pez marino (que puede ser o no sustentable) que en realidad ha sido sustituido por una especie dulceacuicola (ej. tilapia, Oreochromis sp.., o basa, Pangasianodon sp.) producida por técnicas de acuicultura masiva, dentro o fuera de México, y que tiene distintos alcances (Nhu et al., 2016). Al intercambiar la identidad de las especies comerciales de pescado, algunas de ellas restringidas de la pesca comercial (ej., aquellas reservalas a la pesca deportiva, como marlin, pez vela, pez espada, dorado, etc. dof 16/03/1994 y dof 25/11/2013) o en peligro de extinción, como algunos tiburones y peces incluidos en la lista roja de la Unión Internacional para la Conservación de la Natur aleza (uicn), pueden ser comercializadas de manera discreta o anónima, lo que puede representar un obstáculo a manejo y la conservación oficiente de estos recursos pesqueros o amenazados por la sobreexplotacion.

Preparado por: Adrián Munguía-Vega $\mathrm{PhD}$ (consultor independiente)

\section{Marzo de 2019} sustitución de especies de peces marinos pueden ser altos, aunque, en general. al. 2016). Sin embarco pocos estudios de sustitución de especies de peces se han realizado en América Latina incluyendo Belice (Cox et al 2013). Costa Rica (O'Bryhim et a 2017) Chile (Sebastian et al. 2008). Perú (Marin et al 2018) yvarios estudios realizados en Brasil (Carvalho et al. 2017; Staffen et al, 2017; Veneza etal. 2018).

DOI 10.31230/osf.io/49wka

En México, un primer estudio con un tamaño de muestra muy reducido (n = 6) estuvo enfocado sólo en la venta de bacalao en tiendas, donde se reportó 67 \% de sustitución en Ciudad de México (cdmx) (Lambarrietal. 2015). Un estudio 
reciente con un mayor numero de muestras $(n=134)$, obtenidas de pescaderias de la camx y mercados en el estado de Qun tana Roo, reportó una sustitución promedio de $18 \%$ y la comercialización de especies amenazadas de acuerdo con lauicn (Sarmiento-Camacho y Valdez-Moreno, 2018).

Con el objetivo de conocer la naturaleza y magnitud de la sustitución de especies de pescado en México, y poder ofrecer soluciones especificas, iniciamos el estudio más completo que se ha realizado en el pais hasta el momento, en el que presentamos los resulados de la identificación de 383 muestras individuales

\section{METODOLOGÍA}

El código de barras del adn (dna barcoding) es una técnica forense en la que se aísla un segmento de adn de un gen de referencia (ej., 650 pares de bases de muestra con de la proteína citocromo oxidasa subunidad lo col) a partir de una un platillo de un restaurante La secuencia de adn obtenida es comparada con bases de datos de referencia (ej., GenBank, Bold) para determinar la verdadera identidad de la muestra.

Durante julio, agosto y septiembre de 2018 tomamos un total de 462 muestras en tres distintas ciudades de Mexico: 141 en Mazatlán, 178 en Ciudad de México (cdmx) y 143 en Cancun (tabla 1). Las muestras se distribuyeron entre tres puntos de venta distintos donde los consumidores adquieren pescado en el

país: pescaderías, supermercados y restaurantes.

Tabla 1. Muestras comerciales de pescado recolectadas en tres ciudades distintas de México

\begin{tabular}{lrrrr}
\hline & Mazatlán & \multicolumn{1}{c}{ coMx } & \multicolumn{1}{c}{ Cancún } & \multicolumn{1}{c}{ Total } \\
\hline Pescaderías & 34 & 50 & 38 & $\mathbf{1 2 2}$ \\
Supermercados & 38 & 45 & 36 & $\mathbf{1 1 9}$ \\
Restaurantes & 69 & 83 & 69 & $\mathbf{2 2 1}$ \\
Total & $\mathbf{1 4 1}$ & $\mathbf{1 7 8}$ & $\mathbf{1 4 3}$ & $\mathbf{4 6 2}$ \\
\hline
\end{tabular}

Cabe destacar que la toma de muestras no estuvo enfocada en ninguna especie en particular. Al visitar cada establecimiento, las muestras recolectadas dependieron de la oferta de productos de pescado disponible y se recolectó una muestra de cada uno de los nombres comerciales presentes en cada establecimiento. - Paracadamuestra lasiguienteinformaciónserecolectóeintegróenunabasede datosparacadaunadelastresciudades:paracadamuestraseanotófechayhorade recolección, idúnico, recolector, número de tubo, nombredelestablecimiento,tipo de establecimiento (pescadería, supermercado, restaurante), nombre comercia del pescado, origen del nombre comercial (verbal, etiqueta, menú), presentación del pescado, tratamiento que recibio la muestra (ej., crudo, congelado, ahumado, supermercados) o porción (restaurantes), peso en gramos de la muestra y otros comentarios.

La extracción de adn se realizó siguiendo el método de sales modificado (Miller et al., 1988). Para 137 muestras que no pudieron identificarse genéticamente en un primer intento, probablemente porque mostraron muy baja calidado cantidad de adn, fue necesario hacer extracciones por medio del kit DNeasy Blood an Tissue (Qiagen, Valencia, Estados Unidos) del fabricante.

s pares de primers o secuencias

fanquean la secuencia de

l. (2005), par reportados por Ward et

reacción en cadena de la polimerasa

(pcr) 655 nucleótidos de adn de la

región mitocondrial conocida comoci-

tocromo oxidasa subunidad I (coi).

A partir del adn de las 462 muestras se
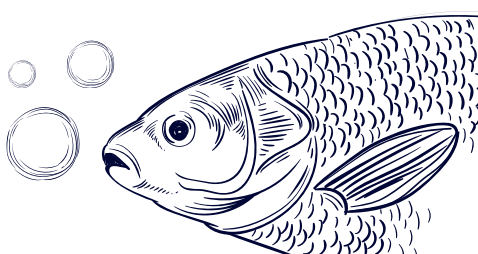

obtuvo la amplificación exitosa de 416 mues-

tras $(90 \%)$, las cuales se enviaron a analizar en un se-

cuenciador Applied Biosystems 3730 Xl. Las secuencias forward

y reverse resultantes fueron analizadas y editadas manualmente para obtener la secuencia final consenso de cada muestra, con ayuda del programa en linea Benchling (https://benchling.com). Se realizo un alineamiento múltiple de todas las rificó que las sec algoritmo Clustal W en el programa Mega7, con el que se veinterrupciones, $y$ se ras obtenidas codificaran la proteina de

De las 416 muestras secuencia secuencias 383 secuencias $(9206 \%$ tuvieron una calidad suficiente para realizar una identificación genética confozble mientras que las secuencias restantes presentaron una menor calidad (longitudes menores 400 pares de bases o secuencias ruidosas o ambiguas) y no fueron incluidas en los resultados. Esto puede deberse avarios factores, como la heterogeneidad en varias caracteristicas de las muestras, que incluyen el metodo de preservación

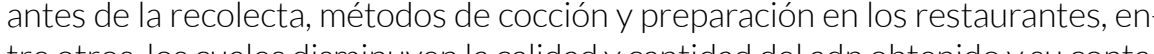
minación con aceites, especias y otros ingredientes.

La identificación genética en el nivel de especie se realizó con base en la secuencia más parecida presente en dos bases de datos distintas. 1. Mediante e algoritmo MegaBlast contra las secuencias depositadas en la base de datos de nucleotidos de adn de acceso abierto GenBank (https:///blast.ncbi.nlm.nih.gov). barcode records). en de código de barras en el nivel de especie (species leve

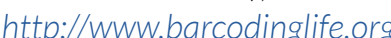

Para determinar la sustitución de especies, se comparó el nombre comercial de cada muestra con tres bases de referencia de acceso abierto que contienen nombres comunes y científicos de peces en México. 1. Especies de interés 
pesquero en el Pacifico mexicano (http://catalogo.cicimar.ipn.mx) (Ramirez-Rodriguez, 2013). 2. El catálogo de peces comerciales mainos de Mexico, de Comisión Nacional cara el Conocimiento y Uso de la Biodiversidad (Conabio) (http://enciclovida.mx/peces). 3. La lista de nombres comunes en español para Mexico, de la base de datos de acceso abierto Fishbase (http://www.ifshbase.org). Se determino que habia una sustitución de especies cuando el nombre común de la especie identificada geneticamente era distinto del nombre comercial con el cual la muestra de pescado fue vendida. Aunque un solo nombre científico puede corresponder a varios nombres comunes y viceversa, se consideró que habla sustitución de especies cuando el nombre comercial con el cual la muestra fue vendida no correspondía al nombre común de la especie identificad

(a) azul" (que corresponde a Thunnus orientalis/Thunnus thynnus). Igualmente, en tres muestras el salmón fue vendido como "silvestre de Alaska" (que corresponde ancorhynchus gorbuscha). Aunque las 13 muestras anteriores correspondie ron a la especie mencionada en los análisis dichas muestras fueron incluidas con

\section{RESULTADOS}

Los resultados que se muestran a continuación se basan en un total de 383 muestras de peces, recolectadas en Mazatlán $(N=123)$, Cludad de México $(N=153)$ y Cancun $(N=107)$. En total, las muestras provienen de 133 establecimientos distintos en Mexico: 41 pescaderias, 22 supermercados y 70 restaurantes. Dado que las muestras fueron recolectadas de acuerdo con la disponibilidad de productos de pescado presentes en cada establecimiento, los resultados son una muestra representativa de la disponibilidad de nombres comerciales y especies presentes en la venta de pescado al consumidor final en cada una de las ciudades durante nuestro periodo de muestreo.

ables obtenidas varió entre 410 y 609 pares de bases, con un promedio de 553.4 pares de bases. Todas las secuencias tuvieron una homología con alguna secuencia en alguna de las lo que se considera que la identificación de especies es confiable Sólo dos muestras en Mazatlán mostrar homologías < $98 \%$ : con la corvina azul (Cynoscion parvipinnis, $92.6 \%$ ) y el bagre tete (Sciades seemanni, $94.5 \%$ ), lo que sugiere que pertenecen a especies que aún no se encuentran representadas en las bases de datos genéticos, por lo que su identificación

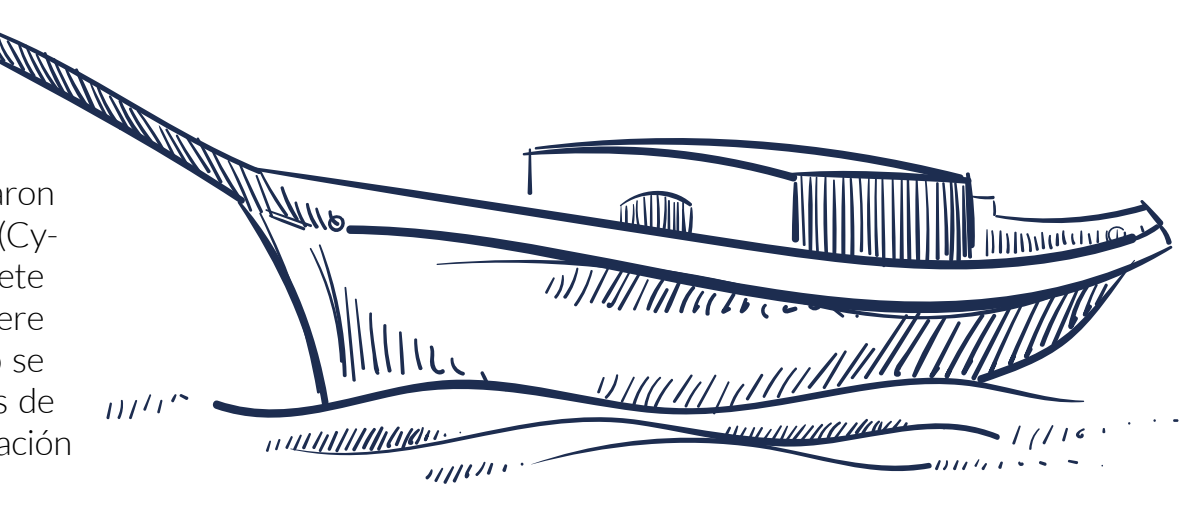

se considera confrable solo en el nivel de genero, pero no de especie. Para la mayoria de las muestras (356, $93 \%$ ), las dos bases de datos coincidieron en la identifcacion de la misma especie. En el $7 \%$ restante, ambas bases de datos coincidieron en la identificación de especies cercanas dentro del mismo genero taxonómico y se eligio la especie con la que la muestra mostraba un mayor porcentaje de homología. En 11 muestras ( $2.8 \%$ del total) no fue posible distinguir entre especies muy cercanas filogenéticamente y que comparten la misma secuencia para el gen Coi, y la identificación realizada incluye a ambas especies (Dasyatis centroura/ Dasyatis guttata, Lutjanus purpureus/Lutjanus campechanus, Makaira nigricans/ Istiompax indica, Merluccius productus/Merluccius angustimanus, Oreochromis

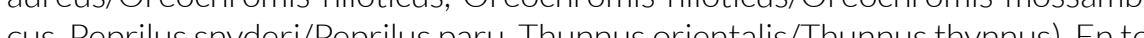
tal se realizó bidentificación en el nivel de especie de 370 muestras individules

La confianza en la asignación de especies fue evaluada mediante e-value, que corresponde al número de resultados que se espera que se produzcan a azar en la base de datos de GenBank, considerando el tamaño de la secuencia obtenid y el número de secuencias presentes en la base de datos. Al respecto, las 383 muestras analizadas mostraron e-values de cero, lo que indica que su similitud con las secuencias en GenBank es estadisticamente confable.

Nombres comerciales y especies encontradas

lemente como "pescado" (vease la seccion "Comercializacion de productos de 'pescado' sin identificar un nombre comercial, al final del documento), 376 muestras identificadas genéticamente se vendieron con 48 nombres comerciales distintos (anexo 1 ). pero representan en realidad 103 especies diferentes de peces identificadas con los análisis genéticos (anexo 2). Es decir que, en promedio, un nombre comercia representa a dos especies biologicas distintas, aunque haya una amplia variación enlacorrespondencia entre nombres cientificos ynombres comerciales.

La diversidad de nombres comerciales empleados en México corresponde solo al $46.6 \%$ de la biodiversidad real de especies de peces encontrada. En cada ciudad, la diversidad de nombres comerciales representó $60 \%$ de las espe

Tabla 2. Número de nombres comerciales, número de especies y porcentaje representado (nombres comerciales/número especies) encontrados en cada una de las tres ciudades muestreadas

\begin{tabular}{lrrr} 
& \multicolumn{1}{c}{ Mazatlán } & \multicolumn{1}{c}{ cDMx } & \multicolumn{1}{c}{ Cancún } \\
\hline Nombres comerciales & 23 & 37 & 23 \\
Especies encontradas & 39 & 60 & 39 \\
Porcentaje representado & $58.9 \%$ & $61.6 \%$ & $58.9 \%$ \\
\hline
\end{tabular}


Del total de las 103 especies distintas encontradas, la mitad (51 especies) estuvieron representadas por una sola muestra (anexo 2). Del resto, en orden de importancia, las cinco especies con mayor frecuencia en el estudio, y que juntas representaron $45.4 \%$ del total de las muestras, fueron:

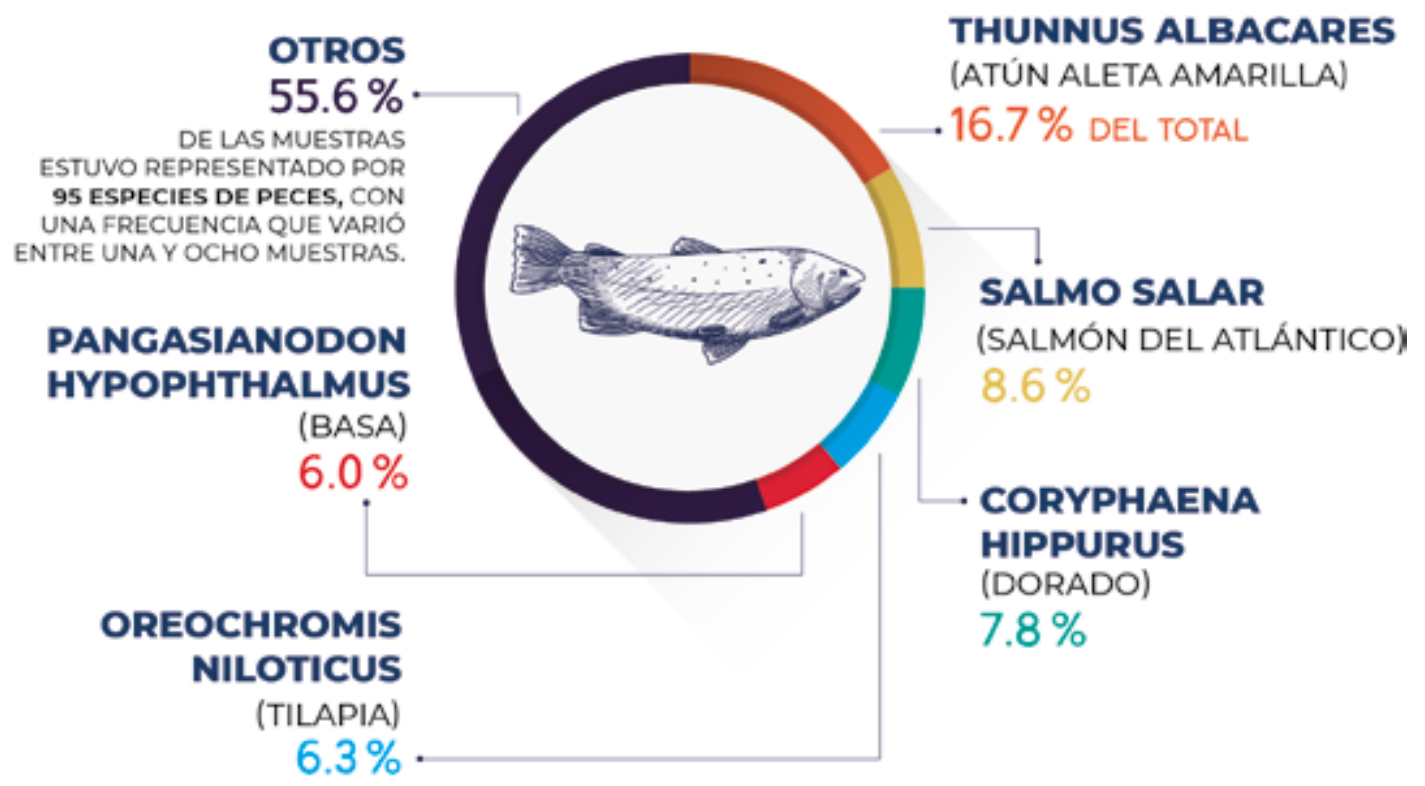

En Mazatlán, del total de las 39 especies encontradas, las especies con mayor frecuencia en el estudio, que representaron $58.5 \%$ del total de las muestras de esa ciudad, fueron identificadas como atún aleta amarilla (Thunnus albacares, 26 muestras), seguidas de dorado (Coryphaena hippurus, 23), salmón del Atlántico (Salmo salar, 8), pez espada (Xiphias gladius, 7) y tilapia (Oreochromis niloticus, 6). Encdmx, del total de las 60 especies encontradas, aquéllas con mayor frecuencia en el estudio y que representan $45 \%$ del total de las muestras de esa ciudad fueron identificadas como thapia (Oreochromis sp., 18 muestras, , atún aleta amatropomus un albacares, 18), salmón del Allántico (Salmo salar, 11), robalo (Centropomus undecimalis, 8), basa (Pangasianodon hypophthalmus, 7 y raya látigo

En Cancún, del total de las 39 especies encontradas, las especies con mayo frecuencia en el estudio y a 39 esresentan $45.7 \%$ del total de las muestras de muestras), salmón delAtlántico (Salmo salar, 14), y basa (Pangasianodon hypophthasmus, 12 muestras). De los 48 nombres

ciales encontrados en México con los cuales se venpresentes en las tres ciudades incluidas en el análisis, sólo 13 (27\%) estuvieron ciudades y la mayoría (26, equivalente a $54.1 \%$ ) de los nombres comerciales fueron exclusivos de una sola ciudad (anexo 1 ).
Sustitución de especies: promedio de las tres ciudades Encontramos un promedio de sustitucion de especies de pescado, en las tres ciudades muestreadas de México, de $30.8 \%$ para 376 muestras vendidas con algún nombre comercial (tabla 3 , excluyendo siete muestras que fueron comercializadas simplemente como " pescado, sin indicar ningún nombre comercial especifíco). El nivel de sustitución en Cancún fue de $26.4 \%$, seguida de Mazatlan $(30.8 \%$ y camx (34\%), aunque las diferencias no fueron significativas entre ciudades (X2 $=1.675 \mathrm{P}=0.432$ ). $\mathrm{Cl}$ promedio de sustitución de especies observado en las tres ciudades muestreadas fue significativamente menor en supermercados (16.6\%)

Tabla 3. Patrón de sustitución de especies en tres ciudades de México ( $\mathrm{N}$ = número de \begin{tabular}{cccc} 
muestras analizadas y, entre paréntesis, número de establecimientos muestreados) \\
\hline Mazatlán
\end{tabular}

\begin{tabular}{lrrrrrrrr}
\multicolumn{1}{c}{$\begin{array}{c}\text { Tipo de } \\
\text { establecimiento }\end{array}$} & N & $\begin{array}{r}\text { \% de } \\
\text { susti } \\
\text { tución }\end{array}$ & N & $\begin{array}{r}\text { \% de } \\
\text { susti } \\
\text { tución }\end{array}$ & N & $\begin{array}{r}\% \text { de } \\
\text { susti } \\
\text { tución }\end{array}$ & N & $\begin{array}{c}\% \text { de } \\
\text { susti } \\
\text { tución }\end{array}$ \\
\hline Pescaderías & 33 & 33.3 & 47 & 44.6 & 27 & 25.9 & 107 & 36.4 \\
Supermercados & $(11)$ & & $(21)$ & & $(9)$ & & $(41)$ & \\
& 24 & 8.3 & 33 & 24.2 & 21 & 14.2 & 78 & 16.6 \\
Restaurantes & $(7)$ & & $(8)$ & & $(7)$ & & $(22)$ & \\
& 63 & 38.0 & 70 & 31.4 & 58 & 31.0 & 191 & 33.5 \\
& $(23)$ & & $(26)$ & & $(21)$ & & $(70)$ &
\end{tabular}
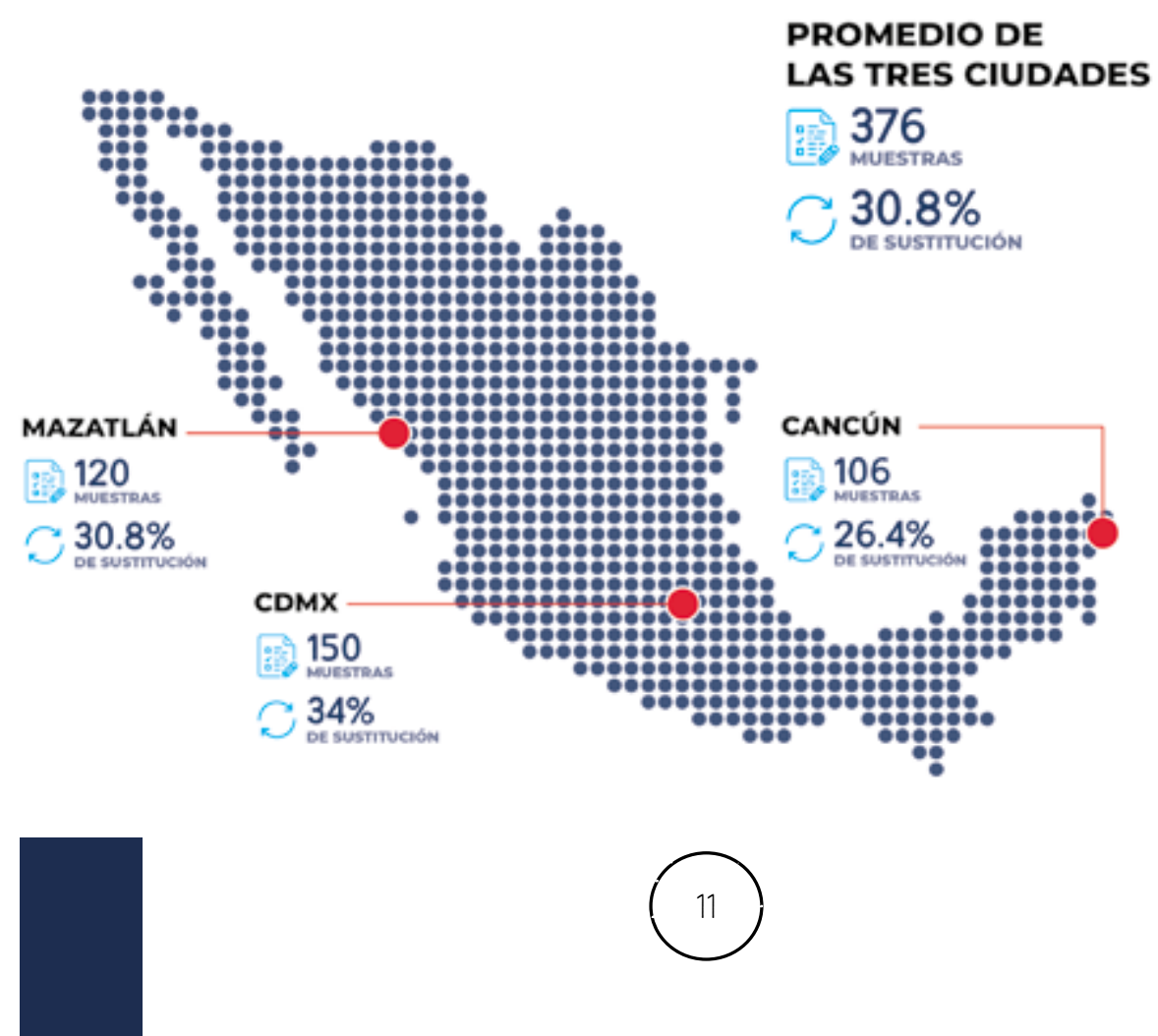
Considerando los 48 nombres comerciales reportados en las tres ciudades, 21 yeron con 322 muestras u 88.3 \% del total (anexo 3). En este grupo de 21 nombres comerciales con un minimo de cinco muestras observamos que los mayores porcentajes de sustitución de especies (> $50 \%$ ) se encontraron en marlin (94.4 $\%$, sierra (88.9\%), mero (86.7\%), huachinango (53.8\%), robalo (53.3\%) y corvina $(53.3 \%)$. Los nombres comerciales que mostraron niveles intermedios de sustitución de especies (33.3-40\%) incluyeron mojarra (40\%), dorado (38.7 \%) cochito (33.3\%), lenguado (33.3\%), peto (33.3\%) y trucha (33.3\%). Los nombres comerciales que mostraron bajos niveles de sustitución de especies (0-11.1\%) tro nombres cona (11.1\%), atun (103\%), castit (9.4\%) y satros (5.1\%). Cuabasa, mantarraya, merluzay pez espada (anexo 3).

\section{Sustitución de especies: tendencias por ciudad}

Respecto a la frecuencia de sustitución de especies en cada ciudad, Mazatlán mostró menor sustitución de especies en supermercados (8.3\%), seguidos de pescaderías (33.3\%) y restaurantes (38\%). En cdmx encontramos una menor con restaurantes (31.4\%) y pescaderías (44.6\%). En Cancún observamos la menor sustitución de especies en supermercados (14.2\%), seguidos de pescaderías (25.9\%) y restaurantes (31\%).

Al comparar los patrones de sustitución de especies en cada ciudad muestreada (anexos 4-6) con el promedio de las tres ciudades muestreadas (anex3), encontramos algunas tendencias interesantes. Los niveles de sustitución de especies de algunos nombres comerciales, como atún, salmón y basa, fueron consistentemente bajos en cada una de las tres ciudades (tabla 4). De manera simlar, otros nombres comerciales mostraron altos niveles de sustitucion en las tres . estuvo presente, como el róbalo.

\section{Tabla 4. Nombres comerciales con patrones constantes de sustitución por ciudad}

\begin{tabular}{|c|c|c|c|c|c|}
\hline \multirow[b]{2}{*}{$\begin{array}{l}\text { Nombre } \\
\text { comercial }\end{array}$} & \multirow[b]{2}{*}{$\mathbf{N}$} & \multicolumn{4}{|c|}{ \% de sustitución de especies } \\
\hline & & $\begin{array}{l}\text { México, } \\
\text { promedio de } \\
\text { tres ciudades }\end{array}$ & Mazatlán & $\operatorname{comx}$ & Cancún \\
\hline Atún & 58 & 10.3 & 14.3 & 10.5 & 5.6 \\
\hline Salmón & 39 & 5.1 & 10 & 0 & 5.9 \\
\hline Basa & 12 & 0 & 0 & 0 & 0 \\
\hline Marlin & 18 & 94.4 & 100 & 83.3 & 100 \\
\hline Robalo & 15 & 53.3 & 66.7 & 50.0 & - \\
\hline
\end{tabular}

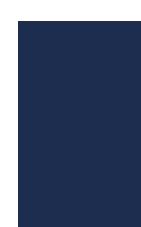

Por otro lado, observamos algunos patrones que contrastan entre las tres ciudades (anexos 3-6). Por ejemplo, el dorado, con $38.7 \%$ de sustitucion promedio en las tres ciudades, tuvo $15.8 \%$ de sustitución en Mazatlan, $85.7 \%$ en cdmxy $60 \%$ en Cancún (tabla 5). La mojarra, que tuvo un promedio de sustitución en las tres ciudades de $40.0 \%$, mostró nula sustitución en Mazatlán, $11.1 \%$ de sustitución en camxy $100 \%$ en Cancén. El huachinango, con un promedio en las tres cludades de $53.8 \%$, tuvo nula sustitución en Mazatlán, $77.8 \%$ en camx y nula sustitu-

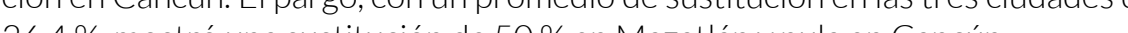

\section{Tabla 5. Nombres comerciales con patrones contrastantes de sustitución por ciudad}

\begin{tabular}{lrrrrr}
$\begin{array}{l}\text { Nombre } \\
\text { comercial }\end{array}$ & $\begin{array}{r}\text { Promedio de } \\
\text { tres ciudades }\end{array}$ & \multicolumn{1}{c}{ Mazatlán } & \multicolumn{1}{c}{ coMx } & \multicolumn{1}{c}{ Cancún } \\
\hline Dorado & 31 & 38.7 & 15.8 & 85.7 & 60.0 \\
Cazón & 32 & 9.4 & 25.0 & 0 & 6.7 \\
Tilapia & 18 & 11.1 & 0 & 0 & 25.0 \\
Mojarra & 15 & 40.0 & 0 & 11.1 & 100 \\
Huachinango & 13 & 53.8 & 0 & 77.8 & 0 \\
Pargo & 11 & 36.4 & 50.0 & - & 0 \\
Mero & 15 & 86.7 & - & 100 & 80.0 \\
\hline
\end{tabular}

\section{Especies y patrones en la sustitución comercial de pescado}

Los patrones de sustitución de especies de los 12 nombres comerciales mas comunes nos permitieron documentar varios aspectos de la complejidad del fenomeno en México (anexo 7). Podemos subdividir los patrones de sustitución de especies en cuatro categor ias principales. sustirución nentre peces pelágicos, sussustitución entre peces marinosy dulceacuícolas de acuicultura.

\section{a) Pez pelágico sustituido por otro pez pelágico}

Entre las especies con mayores niveles de sustitución, el marl lin fue sustituido por tres especies de peces pelágicos (atún aleta amarilla, pejegallo, pez vela) (anexo 7).

b) Pez marino conocido sustituido por otro pez marino desconocido o conocido

El mero fue sustituido por pez fuerte, bagre bandera, blanquillo lucio y sardina crinuda La sierra, por lisa blanca palometa, chano, mojarra aletas amarillasy burrito corcovado. El huachinango, por bagre bandera, lengua y cadernal. El robalo, por corvina boquinaranja, corvina rayada, cobia y conejo amarillo. El pargo, por vieja mexicana, dormilona del Pacífico y corvina boquinaranja. El dorado, por pez espada, palometa, merluza y peto. La mojarra, por sargo rojo y 
c) Tiburón sustituido por un pez marino que no es un elasmobranquio y pez oseo sustituido por un elasmobranquio

El cazon fue sustituido por dos especies de peces marinos, incluyendo la sierra yel pez vela (anexo 7 )

El huachinango fue sustituido por la raya látigo y el marlin por el tiburón zorro en dos ocasiones, y en una ocasión por el tiburón sedoso (anexo 7).

d) Pez marino silvestre sustituido por un pez dulceacuícola de acuicultura; pez dulceacuícola de acuicultura sustituido por otro pez dulceacucola de acuicultura; pez dulceacuícola de acuicultura sustituido por un pez marino

La tiapiá fue utilizada para sustituir dorado, mero y robalo. La carpa plateada sus tityo al robaloy la sierra. La carpa herbivora sustituyó al meroy al cazón. a tilapia fue sustituida en

Dos ocasiones por la basa (anexo 7)

El dorado y el atún aleta amarilla fueron utilizados para sustituir al salmón (anexo 7).

\section{Sustitución de especies: etiquetas, menús}

\section{y comunicación verbal}

Al analizar las tendencias de la sustitución de especies en el promedio de las tres ciudades $y$ considerando el origen del nombre comercial del pescado (etiqueta menú, comunicación verbal), observamos una tendencia en la cual el porcentaje de sustitución fue menor cuando la identificación del nombre comercial se realizó a partir de una etiqueta en un supermercado (17.7\%, tabla 6). La sustitucion aumento un poco cuando la identíicación del nombre comercial se realizo empleando el menu en un restaurante (26.7\%), pero no fue significativamente distinta ( $X 2$ $=2.232, P=0.135)$. La sustitución aumentó significativamente cuando la identifí cacion se realizo a partir de información verbal (hasta $40 \%$, tabla 6) y se compar con la identificación con base en etiquetas $(X 2=12.120, P<0.001)$.

\begin{tabular}{|c|c|c|c|c|c|c|c|c|}
\hline & Mazatlán & $\%$ & CDMx & $\%$ & Cancún & $\%$ & $\begin{array}{c}\text { Total } \\
\text { México }\end{array}$ & $\%$ \\
\hline Verbal & $21(58)$ & 36.2 & $30(64)$ & 46.8 & $17(48)$ & 35.4 & $68(170)$ & 40.0 \\
\hline Etiqueta & $2(24)$ & 7.4 & 9 (34) & 24.3 & $3(21)$ & 13.6 & $14(79)$ & 17.7 \\
\hline Menú & $14(38)$ & 36.8 & $12(52)$ & 23.0 & $8(37)$ & 21.6 & $34(127)$ & 26.7 \\
\hline Total & 37 (120) & 30.8 & 51 (150) & 34.0 & 28 (106) & 26.4 & 116 (376) & 30.8 \\
\hline
\end{tabular}

\section{Comercio de especies en peligro}

Entre las especies identificadas con los análisis genéticos se encontraron 13 especies amenazadas de acuerdo con la lista roja de la uicn (una en peligro crítico. tres en peligro $y$ al menos ocho vulnerables) y ocho especies casi amenazadas (anexo 8). En total, las 21 especies amenazadas o casi amenazadas estuvieron re presentadas por un total de 43 muestras ( $11.2 \%$ de las 383 muestras totales). Destacan dos especies de anguila, nueve de tiburones (cornuda o martillo común zorro, sedoso, aleta de cartón, azul, cazón dientón, toro, cangüay y aleta negra) y nueve de peces (marlin azul/negro, boquinete, mero negrillo y mero extraviado baqueta, huachinango del Golfo, conejo amarillo, cochito reina y lenguado limpio). En el caso del conejo amarillo (clasificado en peligro), se encontro que hubo tras que el tiburón zorro (clasificado como vulnerable) fue vendido en dos ocatras que el tiburon zorlo (clasifcado como vilnerable) fue vendido en dos ocachinango en una ocasión La baqueta (clasificada como vulnerable), como robalo en una ocasión. El cochito reina (clasifcado como casi amenazado), como mojarra en una ocasión No se encontraron especies amenazadas en México incluidas en la nom-059. Es importante mencionar que, aunque estas especies se consideran amenazadas o casi amenazadas por organismos internacionales como la uicn, su aprovechamiento en México no es ilegal.

Cabe mencionar que no se consideraron tres especies que, aunque se encuentran como especies amenazadas en la lista de la uicn en sus rangos geográficos nativos, son especies cuyas muestras analizadas provienen de acuicultura, incluyendo la carpa plateada (Hypophthalmichthys molitrix, casi amenazada), la basa (Pangasianodon hypophthalmus, casi amenazada) y la totoaba (Totoaba macdonaldi, en peligro crítico.

\section{Casos en la zona gris de la sustitución de especies}

Para algunas especies, determinar si existe o no sustitución es un caso un tanto arbitrario. Aunque no fueron consideradas como casos estrictamente de sustitución de especies, de acuerdo con los criterios utilizados en nuestros análisis, las siguientes especies se encuentran en una zona gris de lo que podria considerarse como sustitución de especies. Por ejemplo, nueve de las 14 muestras vend
con el nombre comercial "mojarra”" fueron identificadas como al guna especon el nombre comercial "mojarra" fueron identificadas como alguna espe-
cie del género Oreochromis, que corresponde a la tilapia, un pez dulceacuícola producido en granjas acuícolas. Auncue nombre mojarra por ejemplo, es utilizado para designar a más de 40 especies de peces óseos marinos de siete familias distintas, tan sólo en la costa del Pacífico de México, Fishbase menciona que "mojarra" es un nombre común para las especies de tilapia en México, por lo que no se consideró como un caso de sustitución de especies. Otro caso similar es el del sargo rojo (Pagrus pagrus, familia Sparidae), que fue vendido como "pargo", el cual es un nombre comercial que generalmente se emplea para designar a

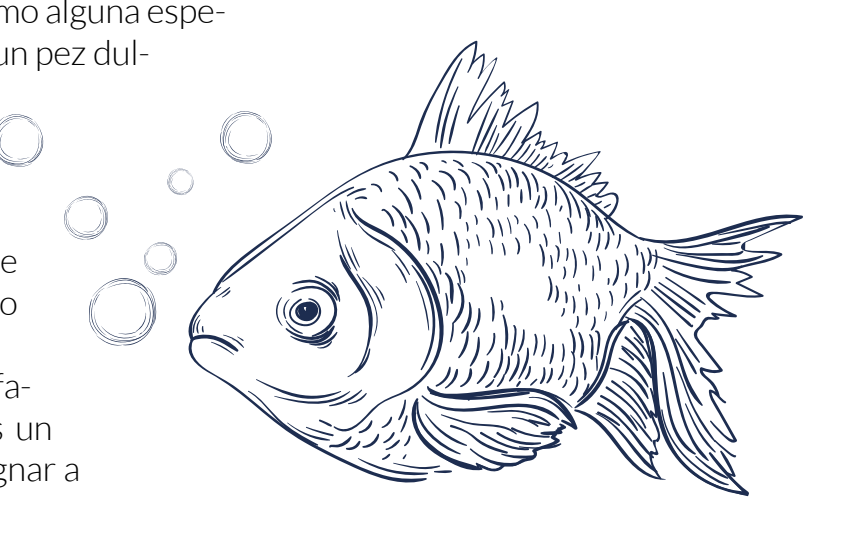


peces de alto valor comercial de la familia Lutjanidae. Sin embargo, la base de datos de peces comerciales de la Conabio menciona que el nombre pargo" también es un nombre común para Pagrus pagrus.

Los casos anteriores nos indican que las estimaciones de sustitución de especon criterios menos flexhles los porcentajes de sus

\section{Comercialización de productos de "pescado" sin identificar} un nombre comercial

En siete ocasiones, todas en supermercados en las tres ciudades muestreadas, se identificaron productos que fueron comercializados simplemente como "pescado, sin mencionar nusun nombre comercial en especifco. Estos productos eran en los cálculos de sustitución de especies, los análisis genéticos identificaron las siguientes especies en dichas muestras: merluza panameña (Merluccius angustimanus) y basa (Pangasianodon hypophthalmus) en Mazatlán: basa (Pangasianodon hypophthalmus), merluza norteña (Merluccius productus) y horqueta del Atlántico (Chloroscombrus chrysurus), en cdmx y sardina crinuda (Opisthonema libertate) en Cancún.

\section{CONCLUSIONES}

Los resultados del análisis de 383 muestras provenientes de tres ciudades de Mèxico (Mazatlan, cdmxy Cancun) sugieren que la sustitución de especies de pescado ocurre en promedio en una de cada tres muestras analizadas de pescaderías, restaurantes y supermercados del pais. Comparativamente, los niveles de sustitucion promedio en las muestras analizadas fueron menores en supermercados (17\%), comparados con restaurantes y pescaderías (34 a $36 \%$ ).

El muestreo realizado no estuvo enfocado en ninguna especie en particular. por lo que permitio documentar que la diversidad de especies de peces comercializada en las tres ciudades es alta, abarcando la costa del Pacifico (Mazatlán), la costa de Caribe (Cancun) y cdmx, con un registro de al Panos 103 esp

Los nives más altos de sustifintron en nombres comerciales con nivles intermedios de sustitución (33 a 40\%) fueron mojarra dorado cochito lenguado petoy trucha Los niveles más bajos de sustitución de especies (0 a $11 \%$ ) se encontraron en los nombres comerciales tilapiatún salmón basa merluza pezespada y dos nombres genéricos empleados para referirse a cualquier tiburón juvenil o de talla pequeña (cazón), y a cualquier pez plano miembro de los elasmobranquios (mantarraya).

Algunos nombres comerciales mostraron patrones similares en las tres ciudades muestreadas, tanto con bajos niveles de sustitución (ej. atún, salmón, basa como con altos niveles de sustitucion (marlin). Otros nombres comerciales mosmojarra, huachinango y pargo. Encontramos que los niveles de sustitución de especies en el promedio de las tres ciudades muestreadas fueron menores cuando la identificación del nombre comercial de la muestra se realizo con base en información escrita (etiqueta o menú en restaurante, respectivamente 18 a $27 \%$ de sustitución), comparados conniveles de surtifución mayores cuan do ción se realizo solo con informacionverbal (sustitución de 40\%).

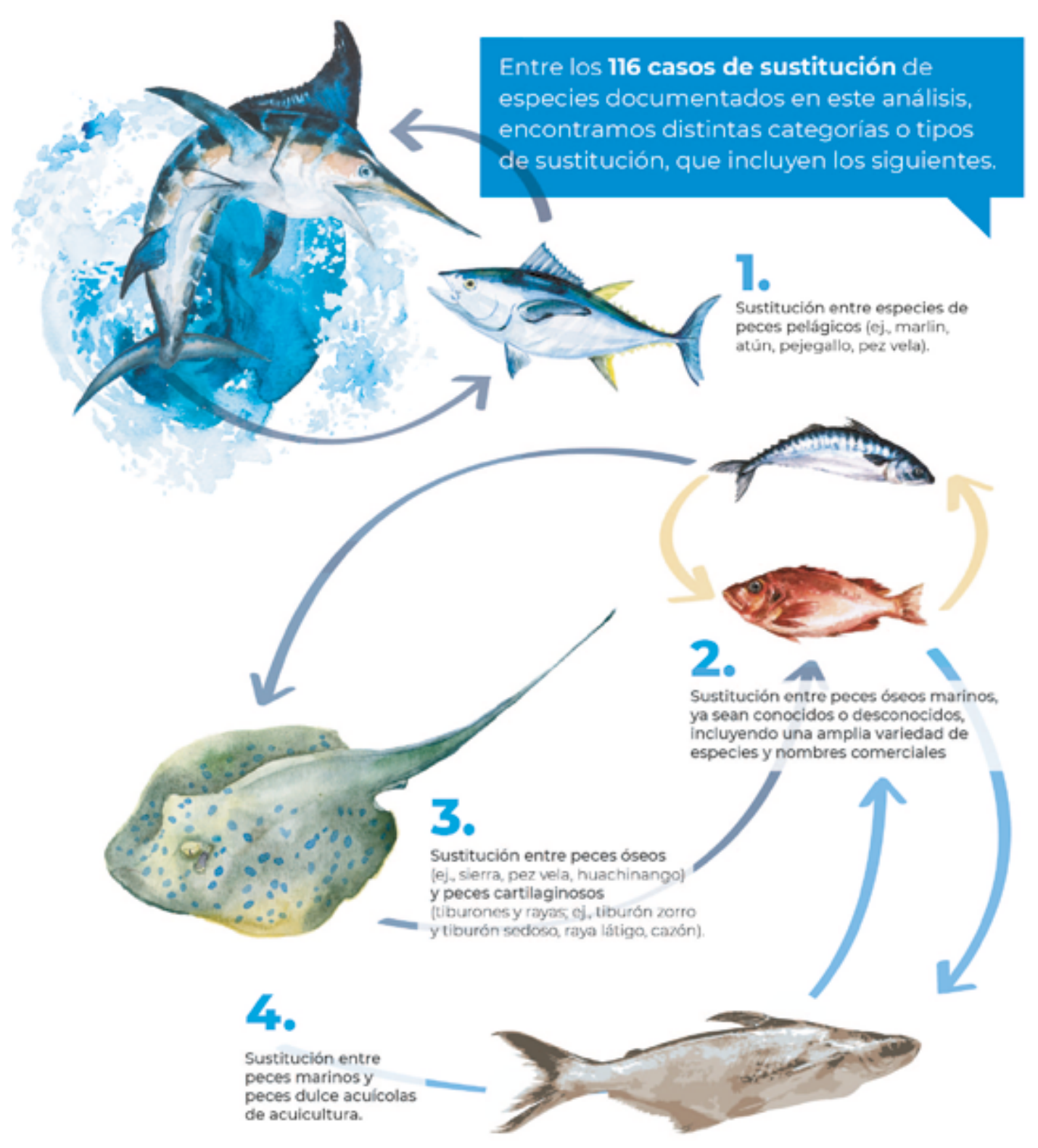


Registramos el comercio de 13 especies amenazadas y ocho casi amenazadas, de acuerdo con la lista roja de la uicn. Entre las especies anmenazadas, registranos, des dos especies de anguillas, tiburón martillo comunn, pez conejo amarilio, atún aleta azul, tiburón zorro, tiburón sedoso, marlin azul/negro, tiburón aleta de cartón mero extraviado, boquinete, baqueta y huachinango del Golfo. En al menos sel's

\section{RECOMENDACIONES}

Los resultados que se presentan en este reporte son representativos de sólo tres ciudades (Mazatlán, cdmx y Cancún) y de los patrones de comercialización de pescado en ellas durante la temporada de muestreo (verano de 2018). Dado que, pescado, nombres comerciales y parrones de sustitución de especies en distintas regiones de México, es necesario realizar estudios posteriores que permitan documentar los patrones de sustitución de especies en otros lugares del país y su variación a lo largo de las distintas temporadas del año.

Aunque el presente estudio sugiere que, en general, hay $30 \%$ de sustitución en las especies de pescado en México, los análisis realizados no permiten distinguir cuáles son las causas detrás de la sustitución de especies, ni si dicha sustitución es accidental o intencional. Con la información obtenida, tampoco es posible determinar en qué punto de la cadena comercial ocurrió la sustitución de especies en las muestras. Por lo tanto, se recomienda realizar estudios que permitan distinguir las causas probables de la sustitución de especies (ej., ineficacia en la trazabilidad de la información, error humano, fraude económico, etc.), asi como distinguir los puntos clave en las cadenas comerciales de pescado donde ocurre dicha sustitucion de especies.

Los resultados sobre la frecuencia en la sustitución de especies en el comercio de pescados destacan la necesidad de garantizar el flujo de información sobre la identidad y el origen real de las especies a partir de la cadena comercial, y de establecer estandares en la trazabilidad de la información hasta el consumidor final. La transparencia en el flujo de información veraz sobre la identidad del pescadas pra evitar su sobrexplotación, promover beneficios económicos para los productores y pescadores que dependen

directamente de la venta de productos pesqueros, $y$ permitir que el consumido final pueda realizar decisiones informadas sobre lo que consume. Por otro lado, la flaqueza en la custodia de la información sobre

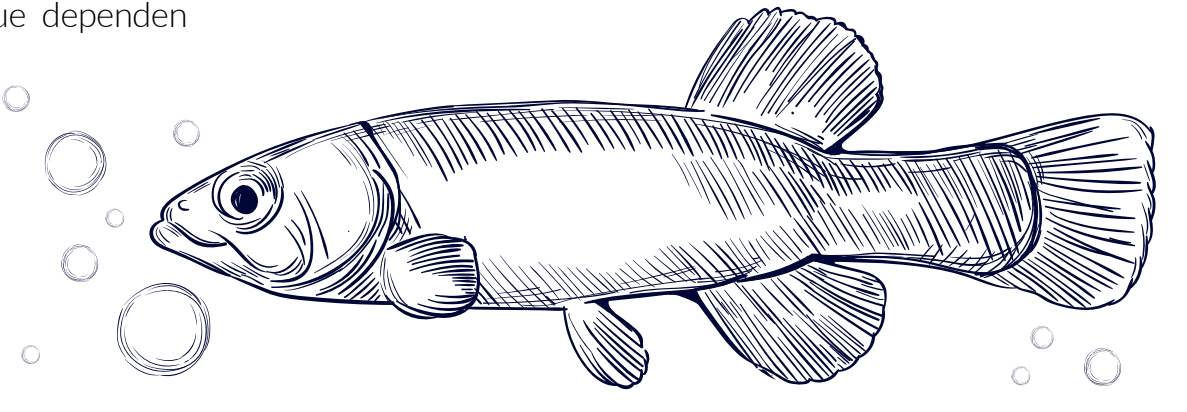

la cadena de comercialización del pescado, que permite que exista la sustitucion de especies, abre las puertas para la comercialización de la pesca ilegal.

Finalmente, hay la necesidad de crear una lista oficial (ej., avalada por autoridades pesqueras en México) que relacione los nombres científicos de las especies con los nombres comerciales aceptados para cada una, con el fin de tener una lista de referencia única y actualizada que permita distingur los casos de sustitución de especies, incluyendo si se trata de una especie marina silvestre o una de agua

.

\section{Datos detallados de cada muestra analizada}

Los detalles de cada una de las 383 muestras analizadas e incluidas en este reporte pueden consultarse en el anexo 9

https://gatoxliebre.org/wp-content/uploads/2019/03/Anexo 9-Base-de-Datos.xlsx

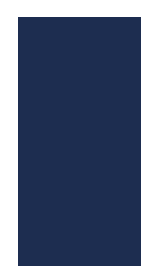

Anexo 1.

Lista de 48 nombres comerciales, su presencia en tres distintas ciudades de Méxicoy el número de muestras analizado ( $N$ ). Siete muestras vendidas con el nombre comercial "pescado" no fueron incluidas en esta lista, la cual está ordenada por N de mayor a menor.

\begin{tabular}{llll}
\hline Núm. & $\begin{array}{l}\text { Nombre } \\
\text { comercial }\end{array}$ & $\begin{array}{c}\text { Ciudades en las } \\
\text { que estuvo } \\
\text { presente }\end{array}$ & $\mathbf{N}$ \\
\hline 1 & Atún & 3 & $\mathbf{5 8}$ \\
2 & Salmón & 3 & $\mathbf{3 9}$ \\
3 & Cazón & 3 & $\mathbf{3 2}$ \\
4 & Dorado & 3 & $\mathbf{3 1}$ \\
5 & Marlin & 3 & 18 \\
6 & Tilapia & 3 & 18 \\
7 & Mero & 2 & $\mathbf{1 5}$
\end{tabular}




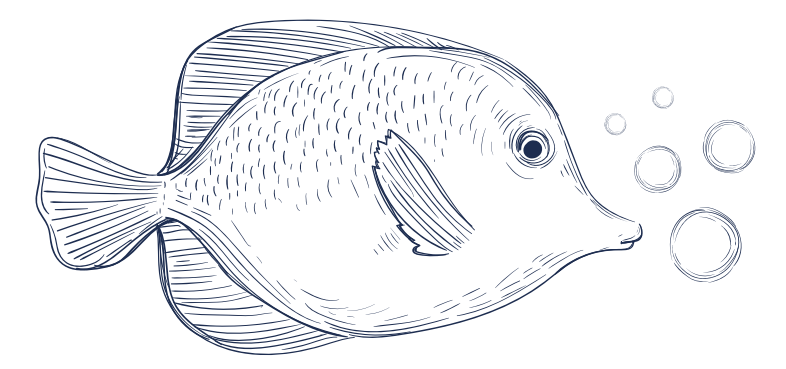

Robalo

Mojarra

Huachinango

15

Pargo

Sierra

Curvina

Cochito

Lenguado

Peto

Trucha

Mantarraya

Merluza

Pez espada

Esmedregal

Hamachi

Bacalao

Botete

Pez vela

Abadejo

Anguila

Boquinete

Lisa

Coronado

Jurel

Anchoa del

Cantábrico

Black Cod

Garropa

Pajarito

Pámpano

\begin{tabular}{llll}
38 & Totoaba & 1 & 1 \\
39 & Xcochin & 1 & 1 \\
40 & Blanco de & 1 & 1 \\
& oriente & & \\
41 & Charal & 1 & 1 \\
42 & Lobina & 1 & 1 \\
43 & Pescado blanco & 1 & 1 \\
44 & Pez bobo & 1 & 1 \\
45 & Pez volador & 1 & 1 \\
46 & Sea bass & 1 & 1 \\
47 & Tiburón azul & 1 & 1 \\
48 & Tiburón guitarra & 1 & 1 \\
\hline & Total & & 376 \\
\hline
\end{tabular}

Anexo 2.

Lista de 103 especies identificadas por métodos genéticos, número de muestras de cada especie (N), porcentaje de frecuencia respecto al total (383 muestras) y frecuencia acumulada. La lista está ordenada por $\mathrm{N}$, de mayor a menor.

\begin{tabular}{llrrr}
\hline Núm. & Nombre cientifico & N & \multicolumn{1}{c}{$\%$} & \% acumulado \\
\hline 1 & Thunnus albacares & 64 & 16.7 & 16.7 \\
2 & Salmo salar & 33 & 8.6 & 25.3 \\
3 & Coryphaena hippurus & 30 & 7.8 & 33.2 \\
4 & Oreochromis niloticus & 24 & 6.3 & 39.4 \\
5 & Pangasianodon hypophthalmus & 23 & 6.0 & 45.4 \\
6 & Centropomus undecimalis & 8 & 2.1 & 47.5 \\
7 & Prionace glauca & 8 & 2.1 & 49.6 \\
8 & Xiphias gladius & 8 & 2.1 & 51.7 \\
9 & Carcharhinus falciformis & 7 & 1.8 & 53.5 \\
10 & Dasyatis americana & 7 & 1.8 & 55.4 \\
11 & Scomberomorus cavalla & 6 & 1.6 & 56.9 \\
12 & Seriola rivoliana & 6 & 1.6 & 58.5
\end{tabular}


Balistes polylepis

Oncorhynchus gorbuscha

Pagrus pagrus

Rhizoprionodon terraenovae

Hypophthalmichthys molitrix

Mustelus canis

Oncorhynchus mykiss

Acanthocybium solandri

Anoplopoma fimbria

Ctenopharyngodon idella

Lutjanus colorado

Lutjanus guttatus

Merluccius productus

Merluccius productus/Merluccius angustimanus

Oreochromis aureus

Peprilus snyderi/Peprilus paru

Seriola dumerili

Seriola quinqueradiata

Alopias pelagicus

Bagre marinus

Balistes vetula

Brotula clarkae

Carcharhinus leucas

Centropomus viridis

Cynoscion reticulatus

Cynoscion xanthulus

Gadus chalcogrammus

Hyporthodus flavolimbatus

Istiophorus platypterus

Lachnolaimus maximus

Lutjanus griseus

Mugil cephalus

Oncorhynchus keta

$\begin{array}{lll}5 & 1.3 & 59.8 \\ 5 & 1.3 & 61.1 \\ 5 & 1.3 & 62.4 \\ 5 & 1.3 & 63.7 \\ 4 & 1.0 & 64.8 \\ 4 & 1.0 & 65.8 \\ 4 & 1.0 & 66.8 \\ 3 & 0.8 & 67.6 \\ 3 & 0.8 & 68.4 \\ 3 & 0.8 & 69.2 \\ 3 & 0.8 & 70.0 \\ 3 & 0.8 & 70.8 \\ 3 & 0.8 & 71.5 \\ 3 & 0.8 & 72.3 \\ & & \\ 3 & 0.8 & 73.1 \\ 3 & 0.8 & 73.9 \\ 3 & 0.8 & 74.7 \\ 3 & 0.8 & 75.5 \\ 2 & 0.5 & 76.0 \\ 2 & 0.5 & 76.5 \\ 2 & 0.5 & 77.0 \\ 2 & 0.5 & 77.5 \\ 2 & 0.5 & 78.1 \\ 2 & 0.5 & 78.6 \\ 2 & 0.5 & 79.1 \\ 2 & 0.5 & 79.6 \\ 2 & 0.5 & 80.2 \\ 2 & 0.5 & 80.7 \\ 2 & 0.5 & 81.2 \\ 2 & 0.5 & 81.7 \\ 2 & 0.5 & 82.2 \\ 2 & 0.5 & 82.8 \\ 2 & 0.5 & 83.3\end{array}$

Opisthonema libertate

Oreochromis

niloticus/Oreochromis

mossambicus

Rachycentron canadum

Scomberomorus sierra

Sphyraena barracuda

Thunnus orientalis/Thunnus

thynnus

Anchoa lyolepis

Anguilla anguilla

Anguilla rostrata

Bodianus diplotaenia

Carcharhinus acronotus

Carcharhinus brevipinna

Carcharhinus plumbeus

Caulolatilus microps

Cephalopholis fulvo

Chanos chanos

Chloroscombrus chrysurus

Cynoscion albus

Cynoscion parvipinnis

Dasyatis centroura/Dasyatis guttata

Diapterus brevirostris

Engraulis encrasicolus

Epinephelus guttatus

Gadus macrocephalus

Hemiramphus saltator

Hyporthodus acanthistius

Lobotes pacificus

Lopholatilus chamaeleonticeps

Lutjanus analis

Lutjanus campechanus
20.5

0.5

83.8

84.3

84.9

85.4

85.9

86.4

86.7

86.9

87.2

87.5

87.7

88.0

88.3

88.5

88.8

89.0

89.3

89.6

89.8

90.1

90.3

90.6

90.9

91.1

91.4

91.6

91.9

92.2

92.4

92.7
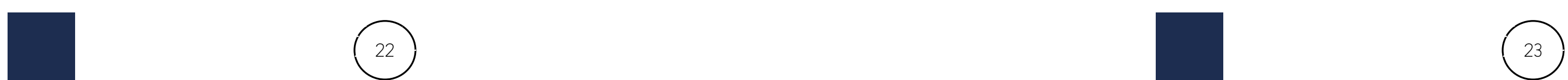
Lobotes pacificus

Lopholatilus chamaeleonticeps

Lutjanus analis

Lutjanus campechanus

Lutjanus novemfasciatus

Lutjanus purpureus/Lutjanus

campechanus

Lutjanus vivanus

Makaira nigricans/Istiompax

indica

Mallotus villosus

Merluccius angustimanus

Merluccius australis

Mugil curema

Mustelus californicus

Mustelus henle

Mycteroperca bonaci

Nematistius pectoralis

Oreochromis

aureus/Oreochromis niloticus

Oreochromis mossambicus

Orthopristis chalceus

Paralichthys californicus

Paralichthys lethostigma

Paranthias colonus

Pleuronectes platessa

Sciades seemanni

Sphoeroides annulatus

Sphoeroides lispus

Sphyraena ensis

Sphyrna lewini

Thunnus albacares/Thunnus

tonggol

101 Totoaba macdonaldi

$\begin{array}{lll}1 & 0.3 & 91.9 \\ 1 & 0.3 & 92.2 \\ 1 & 0.3 & 92.4 \\ 1 & 0.3 & 92.7 \\ 1 & 0.3 & 93.0 \\ 1 & 0.3 & 93.2 \\ 1 & 0.3 & 93.5 \\ 1 & 0.3 & 93.7 \\ & & \\ 1 & 0.3 & 94.0 \\ 1 & 0.3 & 94.3 \\ 1 & 0.3 & 94.5 \\ 1 & 0.3 & 94.8 \\ 1 & 0.3 & 95.0 \\ 1 & 0.3 & 95.3 \\ 1 & 0.3 & 95.6 \\ 1 & 0.3 & 95.8 \\ 1 & 0.3 & 96.1 \\ & & \\ 1 & 0.3 & 96.3 \\ 1 & 0.3 & 96.6 \\ 1 & 0.3 & 96.9 \\ 1 & 0.3 & 97.1 \\ 1 & 0.3 & 97.4 \\ 1 & 0.3 & 97.7 \\ 1 & 0.3 & 97.9 \\ 1 & 0.3 & 98.2 \\ 1 & 0.3 & 98.4 \\ 1 & 0.3 & 98.7 \\ 1 & 0.3 & 99.0 \\ 1 & 0.3 & 99.2 \\ & & \\ 1 & 0.3 & 99.5\end{array}$

\begin{tabular}{llrrr}
102 & Trachinotus carolinus & 1 & 0.3 & 99.7 \\
103 & Xystreurys liolepis & 1 & 0.3 & 100.0 \\
\hline & Total & $\mathbf{3 8 3}$ & & $\mathbf{1 0 0 . 0}$ \\
\hline
\end{tabular}

Anexo 3.

Frecuencia en la sustitución de especies en México (promedio de las tres ciudades muestreadas) para los 21 nombres comerciales con cinco o más muestras muestras que fueron sustituidas por otra especie y porcentaje de sustitución de especies. La lista está ordenada por porcentaje de sustitución de especies, de mayor a menor.

\begin{tabular}{llrrr}
\hline Núm. & $\begin{array}{c}\text { Nombre } \\
\text { comercial }\end{array}$ & N & $\begin{array}{c}\text { Frecuencia de } \\
\text { sustitución } \\
\text { de especies }\end{array}$ & $\begin{array}{c}\text { \% de } \\
\text { sustitución de } \\
\text { especies }\end{array}$ \\
\hline 1 & Marlin & 18 & 17 & 94.4 \\
2 & Sierra & 9 & 8 & 88.9 \\
3 & Mero & 15 & 13 & 86.7 \\
4 & Huachinango & 13 & 7 & 53.8 \\
5 & Robalo & 15 & 8 & 53.3 \\
6 & Curvina & 6 & 3 & 50.0 \\
7 & Mojarra & 15 & 6 & 40.0 \\
8 & Dorado & 31 & 12 & 38.7 \\
9 & Pargo & 11 & 4 & 36.4 \\
10 & Cochito & 6 & 2 & 33.3 \\
11 & Lenguado & 6 & 2 & 33.3 \\
12 & Peto & 6 & 2 & 33.3 \\
13 & Trucha & 6 & 2 & 33.3 \\
14 & Tilapia & 18 & 2 & 11.1 \\
15 & Atún & 58 & 6 & 10.3
\end{tabular}




\begin{tabular}{llrrr}
16 & Cazón & 32 & 3 & 9.4 \\
17 & Salmón & 39 & 2 & 5.1 \\
18 & Basa & 12 & 0 & 0.0 \\
19 & Mantarraya & 6 & 0 & 0.0 \\
20 & Merluza & 5 & 0 & 0.0 \\
21 & Pez espada & 5 & 0 & 0.0 \\
\hline & Total & $\mathbf{3 3 2}$ & $\mathbf{9 9}$ & $\mathbf{2 9 . 8 1}$ \\
\hline
\end{tabular}

Anexo 4.

Frecuencia en la sustitución de especies en Mazatlán para los 23 nombres comer-

(N) númerode muestrando nombre comercial, número de muestras analizadas

sustitución de especies. La lista esta ordenada por N, de mayor a menor.

\begin{tabular}{|c|c|c|c|c|}
\hline & Mazatlán & & & \\
\hline Núm. & $\begin{array}{c}\text { Nombre } \\
\text { comercial }\end{array}$ & $\mathbf{N}$ & $\begin{array}{l}\text { Frecuencia de } \\
\text { sustitución }\end{array}$ & $\begin{array}{c}\text { \% de } \\
\text { sustitución }\end{array}$ \\
\hline 1 & Atún & 21 & 3 & 14.3 \\
\hline 2 & Dorado & 19 & 3 & 15.8 \\
\hline 3 & Salmón & 10 & 1 & 10.0 \\
\hline 4 & Cazón & 8 & 2 & 25.0 \\
\hline 5 & Marlin & 8 & 8 & 100.0 \\
\hline 6 & Pargo & 8 & 4 & 50.0 \\
\hline 7 & Cochito & 6 & 2 & 33.3 \\
\hline 8 & Sierra & 6 & 6 & 100.0 \\
\hline 9 & Curvina & 5 & 2 & 40.0 \\
\hline 10 & Pez espada & 5 & 0 & 0.0 \\
\hline 11 & Tilapia & 5 & 0 & 0.0 \\
\hline 12 & Botete & 3 & 1 & 33.3 \\
\hline 13 & Robalo & 3 & 2 & 66.7 \\
\hline 14 & Basa & 2 & 0 & 0.0 \\
\hline 15 & Huachinango & 2 & 0 & 0.0 \\
\hline
\end{tabular}

\begin{tabular}{llrrr}
16 & Lenguado & 2 & 1 & 50.0 \\
17 & Hamachi & 1 & 0 & 0.0 \\
18 & Mantarraya & 1 & 0 & 0.0 \\
19 & Merluza & 1 & 0 & 0.0 \\
20 & Mojarra & 1 & 0 & 0.0 \\
21 & Pajarito & 1 & 0 & 0.0 \\
22 & Pez vela & 1 & 1 & 100.0 \\
23 & Sea bass & 1 & 1 & 100.0 \\
\hline & Total & $\mathbf{1 2 0}$ & $\mathbf{3 7}$ & $\mathbf{3 0 . 8}$ \\
\hline
\end{tabular}

Anexo 5.

Frecuencia en la sustitución de especies en cdmx para los 37 nombres comercia-

les observados, indicando nombre comercial, número de muestras analizadas (N).

número de muestras que fueron sustituidas por otra especie y porcentaje de Sustitución de especies. La lista está ordenada por $\mathrm{N}$, de mayor a menor.

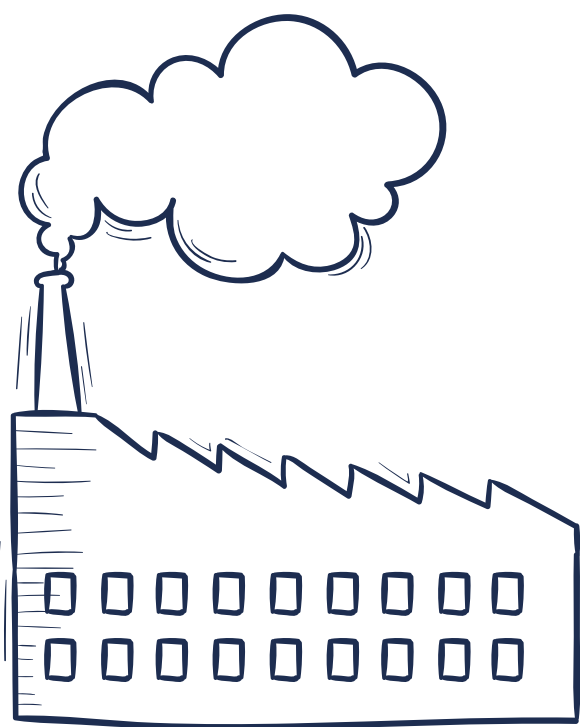

\begin{tabular}{llrrr}
\hline Núm. & Comx & Nombre & N & \multicolumn{2}{c}{$\begin{array}{c}\text { Frecuencia de } \\
\text { sustitución }\end{array}$} & $\begin{array}{c}\text { \% de } \\
\text { sustitución }\end{array}$ \\
\hline 1 & comercial & 19 & 2 & 10.5 \\
2 & Atún & 12 & 6 & 50.0 \\
3 & Robalo & 12 & 0 & 0.0 \\
4 & Salmón & 9 & 0 & 0.0 \\
5 & Cazón & 9 & 7 & 77.8 \\
6 & Huachinango & 9 & 1 & 11.1 \\
7 & Mojarra & 9 & 6 & 85.7 \\
8 & Dorado & 7 & 5 & 83.3 \\
9 & Marlin & 6 & 2 & 33.3 \\
10 & Peto & 6 & 2 & 33.3 \\
11 & Trucha & 6 & 0 & 0.0 \\
12 & Basa & 5 & 5 & 100.0 \\
13 & Mero & 5 & 0 & 0.0
\end{tabular}




\begin{tabular}{llrrr}
14 & Mantarraya & 4 & 0 & 0.0 \\
15 & Bacalao & 3 & 1 & 33.3 \\
16 & Esmedregal & 3 & 1 & 33.3 \\
17 & Lenguado & 3 & 1 & 33.3 \\
18 & Merluza & 3 & 0 & 0.0 \\
19 & Sierra & 3 & 2 & 66.7 \\
20 & Abadejo & 2 & 0 & 0.0 \\
21 & Jurel & 2 & 1 & 50.0 \\
22 & Pez vela & 2 & 2 & 100.0 \\
23 & Anchoa del & 1 & 0 & 0.0 \\
& Cantábrico & & & \\
24 & Anguila & 1 & 0 & 0.0 \\
25 & Black Cod & 1 & 0 & 0.0 \\
26 & Blanco de & 1 & 1 & 100.0 \\
27 & Charal & 1 & 1 & 100.0 \\
28 & Garropa & 1 & 0 & 0.0 \\
29 & Hamachi & 1 & 0 & 0.0 \\
30 & Lisa & 1 & 0 & 0.0 \\
31 & Lobina & 1 & 1 & 100.0 \\
32 & Pámpano & 1 & 0 & 0.0 \\
33 & Pez bobo & 1 & 1 & 100.0 \\
34 & Pez volador & 1 & 1 & 100.0 \\
35 & Tiburón azul & 1 & 1 & 100.0 \\
36 & Tiburón & 1 & 1 & 100.0 \\
& guitarra & & & \\
37 & Totoaba & 1 & 0.0 \\
\hline & Total & $\mathbf{1 5 0}$ & $\mathbf{5 1}$ & 34.0 \\
\hline
\end{tabular}

\begin{tabular}{|c|c|c|c|c|}
\hline & Cancún & & & \\
\hline Núm. & $\begin{array}{l}\text { Nombre } \\
\text { comercial }\end{array}$ & $\mathbf{N}$ & $\begin{array}{l}\text { Frecuencia de } \\
\text { sustitución }\end{array}$ & $\begin{array}{c}\text { \% de } \\
\text { sustitución }\end{array}$ \\
\hline 1 & Atún & 18 & 1 & 5.6 \\
\hline 2 & Salmón & 17 & 1 & 5.9 \\
\hline 3 & Cazón & 15 & 1 & 6.7 \\
\hline 4 & Mero & 10 & 8 & 80.0 \\
\hline 5 & Tilapia & 8 & 2 & 25.0 \\
\hline 6 & Basa & 5 & 0 & 0.0 \\
\hline 7 & Dorado & 5 & 3 & 60.0 \\
\hline 8 & Mojarra & 5 & 5 & 100.0 \\
\hline 9 & Marlin & 4 & 4 & 100.0 \\
\hline 10 & Pargo & 3 & 0 & 0.0 \\
\hline 11 & Boquinete & 2 & 0 & 0.0 \\
\hline 12 & Coronado & 2 & 1 & 50.0 \\
\hline 13 & Huachinango & 2 & 0 & 0.0 \\
\hline 14 & Anguila & 1 & 0 & 0.0 \\
\hline 15 & Curvina & 1 & 1 & 100.0 \\
\hline 16 & Esmedregal & 1 & 0 & 0.0 \\
\hline 17 & Hamachi & 1 & 0 & 0.0 \\
\hline 18 & Lenguado & 1 & 0 & 0.0 \\
\hline 19 & Lisa & 1 & 0 & 0.0 \\
\hline 20 & Mantarraya & 1 & 0 & 0.0 \\
\hline 21 & Merluza & 1 & 0 & 0.0 \\
\hline 22 & $\begin{array}{l}\text { Pescado } \\
\text { blanco }\end{array}$ & 1 & 1 & 100.0 \\
\hline \multirow[t]{2}{*}{23} & Xcochin & 1 & 0 & 0.0 \\
\hline & Total & 106 & 28 & 26.4 \\
\hline
\end{tabular}

Anexo 6.

Frecuencia en la sustitución de especies en Cancún para los 23 nombres comer-

ciales observados, indicando nombre comercial, número de muestras analizadas

sustitución de especies. La lista está ordenada por N, de mayor a menor. 
Anexo 7.

Especies identificadas con los análisis genéticos que fueron empleadas para sustituir los 12 nombres comerciales más muestra $N>9$ y que presentaron algún nivel de sustitucion de especies.

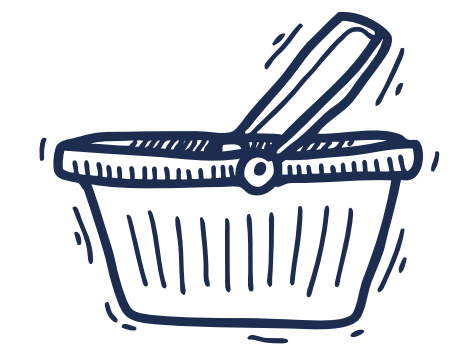

38.7 2 peces espada (Xiphias gladius), 1 palometa (Peprilus sp.), 1 tilapia (Oreochromis aureus), 1 robalo blanco (Centropomus undecimalis), 1 medregal coronado (Seriola dumerili), 1 pez fuerte (Seriola rivoliana), 3 petos (Acanthocybium solandri), 1 merluza (Merluccius sp.), 1 bacalao negro (Anaplopoma fimbria), 1 barracuda del Pacífico (Sphyraena barracuda)

\begin{tabular}{lll}
\hline $\begin{array}{l}\text { Nombre } \\
\text { comercial }\end{array}$ & $\begin{array}{l}\text { \%de } \\
\text { sustitución } \\
\text { promedio de } \\
\text { tres ciudades }\end{array}$ & Especies sustitutas \\
\hline Marlin & 94.4 & $\begin{array}{l}\text { 12 atunes aleta amarilla (Thunnus albacares), 1 pez gallo } \\
\text { (Nematistius pectoralis), 2 tiburones zorro (Alopias } \\
\text { pelagicus), 1 pez vela (Istiophorus platypterus), 1 tiburón } \\
\text { sedoso (Carcharhinus falciformis) }\end{array}$
\end{tabular}

36.41 vieja mexicana (Bodianus diplotaenia), 1 dormilona de Pacifico (Lobotes pacificus), 1 corvina boquinaranja (Cynoscion xanthulus), 1 robalo plateado (Centropomus viridis)

11.12 basas (Pangasianodon hypophthalmus)

10.32 dorados (Coryphaena hippurus), 2 salmones del Atlántico (Salmo salar), 1 cochito (Balistes polylepis), 1

Cazón

9.4 1 sierra (Scomberomorus sierra), 1 carpa herbivor (Ctenopharyngodon idella), 1 pez vela (Istiophorus chano (Chanos chanos), 1 mojarra aleta amarilla (Diapterus brevirostris), 1 carpa plateada (Hypophthalmichthys molitrix), 1 carito o peto (Scomberomorus cavalla), 1 burrito corcovado (Orthopristis chalceus)

86.75 basas (Pangasianodon hypophthalmus), 1 pez fuerte (Seriola rivoliana), 1 robalo blanco (Centropomus undecimalis), 1 tilapia (Oreochromis niloticus), 1 carpa herbivora (Ctenopharyngodon idella), 1 bagre bandera (Bagre marinus), 1 blanquillo lucio (Caulolatilus microps) 1 cabrilla roja (Cephalopholis fulva), 1 sardina crinuda (Opisthonema libertate)

Huachinango $\quad 53.81$ raya látigo blanca (Dasyatis americana), 1 pez fuerte (Seriola rivoliana), 1 mero aleta amarilla (Hyporthodus flavolimbatus), 1 bagre bandera (Bagre marinus), 1 lengua rosada (Brotula clarkae), 1 cadernal (Paranthios colonus), 1 dorado (Coryphaena hippurus),

Robalo

53.3 1 corvina boquinaranja (Cynoscion xanthulus), 1 corvina rayada (Cynoscion reticulatus), 2 carpas plateadas (Hypophthalmichthys molitrix), 1 cobia (Rachycentron canadum), 1 pargo colorado (Lutjanus colorado), 1 conejo amarillo (Lopholatilus chamaeleonticeps), 1 tilapia (Oreochromis niloticus), 1 baqueta (Hyporthodus

Mojarra

40.01 dorado (Coryphaena hippurus), 4 sargos rojos (Pagrus pagrus), 1 cochito reina (Balistes vetula),

Salmón 


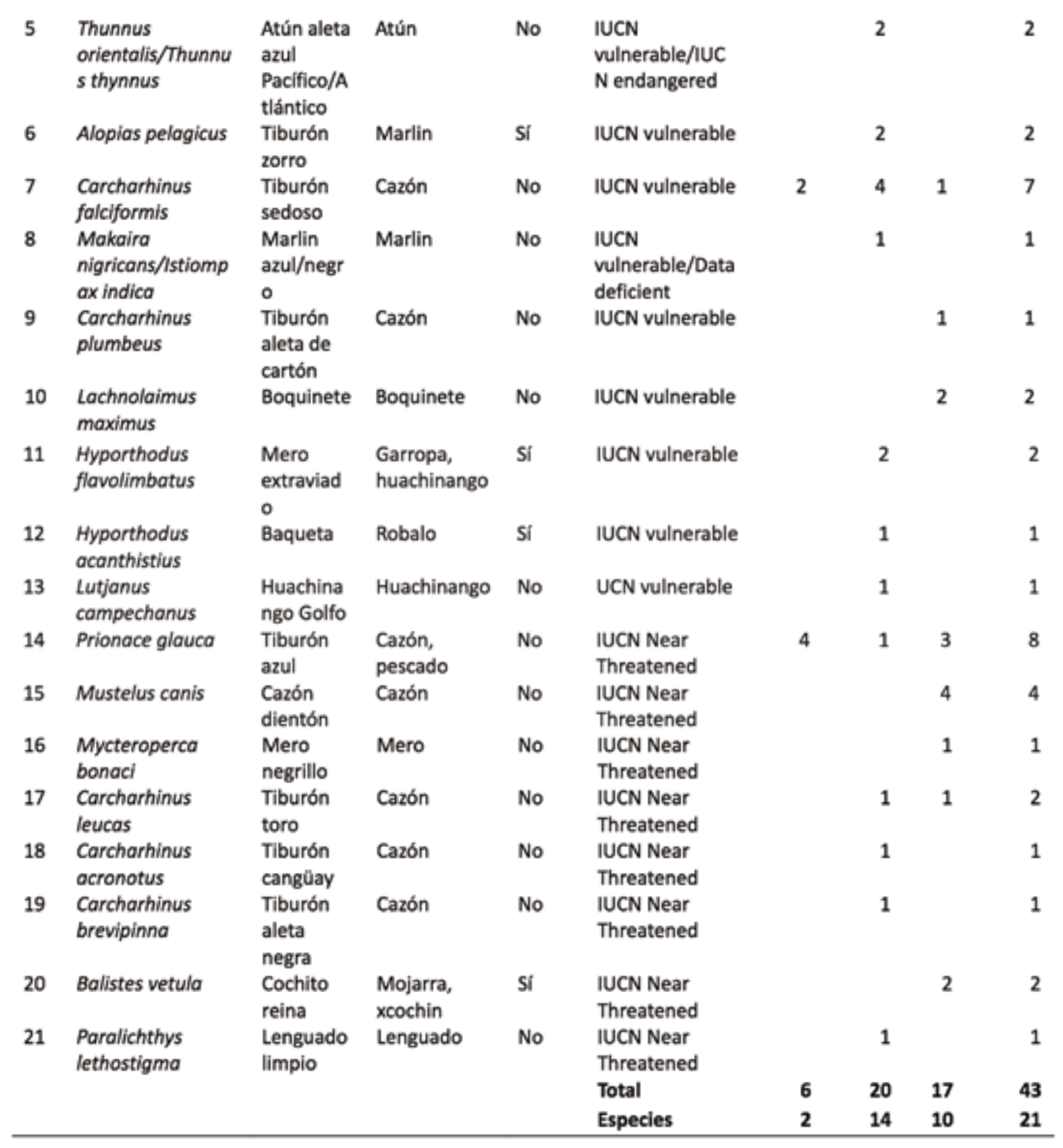

\section{REFERENCIAS}

Carvalho, C. D., D. Guedes, M. G. Trindade, R. M. Sartori-Coelho y P. H. Lima-Araujo.

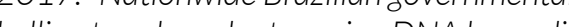
belling trends and rates using DNA barcoding. Fisheries Research 191: 30-35.

Cox, Courtney E., Corbin D. Jones, John P. Wares, Karl D. Castillo, Melanie D. McFieldy John F. Bruno. 2013. "Genetic testing reveals some mislabeling but general compliance

Lambarri, Christian, Héctor Espinosa, Armando Martínez y Ariana Hernández. 2015. "Cods for sale. Do we know what we are buying?". DNA Barcodes 3: 27-29. Y R. Alfaro. 2018 "A glimpse into the genetic diversity of the Peruvian seafood sector: Unveiling species substitution, mislabeling and trade of threatened species". PloS one

Miller. S. A. D. D. Dykes y H. F. Polesky. 1988. "A simple salting out procedure for extracting DNA from human nucleated cells". Nucleic Acids Research 16: 1215.

Nhu, T. T., T. Schaubroeck, P. J. G. Henriksson, R. Bosma, P. Sorgeloos y J. Dewulf. 2016. "Environmental impact of non-certified versus certified (ASC) intensive Pangasius aquaculture in Vietnam, a comparison based on a statistically supported LCA". Environmental Pollution 219: 156-165.

O'Bryhim, Jason R., E. C. M. Parsons y Stacey L. Lance. 2017. "Forensic species identification of elasmobranch products sold in Costa Rican markets". Fisheries Research 186 144-150.

Pardo, M. A., E. Jiménez y B. Pérez-Villarreal. 2016. “Misdescription incidents in seafood sector". Food Control 62: 277-283.

Ramírez-Rodríguez, M. 2013. Especies de interés pesquero en el Pacífico mexicano: nombresy claves para.

Sala, Enric, Octavio Aburto-Oropeza Míriam Reza Gustavo Paredes y Luis G. López-Lemus. 2004. "Fishing down coastal food webs in the Gulf of California". Fisheries 29: $19-25$.

Sarmiento-Camacho, S., y M. Valdez-Moreno. 2018. "DNA barcode identification of commercial fish sold in Mexican markets". Genome 61: 457-466. 
Sebastian, H., P. A. Haye y M. S. Shivji. 2008. "Characterization of the pelagic shark-fin trade in north-central Chile by genetic identification and trader surveys". Journal of Fis Biology 73: 2293-230

Staffen, Clisten Fátima, Mari Dalva Staffen, Mariana Londero Becker, Sara Emelie Löfgren, Yara Costa Netto Muniz, Renato Hajenius Aché de Freitas y Andrea Rita Mation in Brazil" Peer 5 5:e4006.

Stawitz, C. C., M. C. Siple, S. H. Munsch, Q. Leey SAFS Research Derby. 2017. "Financial and Ecological Implications of Global Seafood Mislabeling". Conservation Letters 10: 681-689.

Veneza, Ivana, Raimundo Silva, Leilane Freitas, Sâmia Silva, Kely Martins, Iracilda Sampaio, Horacio Schneider y Grazielle Gomes. 2018. "Molecular authentication of Pargo fillets Lutianus purpureus (Perciformes: Lutianidae) by DNA barcoding reveals commercial fraud". Neotropical Ichthyology 16.

Ward, R. D., T. S Zemlak, B. H. Innes, P. R. Last y P. Hebert. 2005. “DNA barcoding Australia's fish species." Phil. Trans. R. Soc. B: 1847-1857.

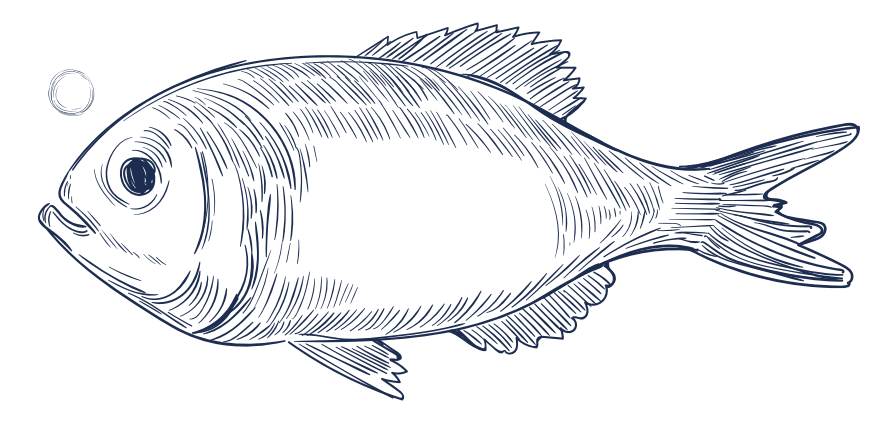




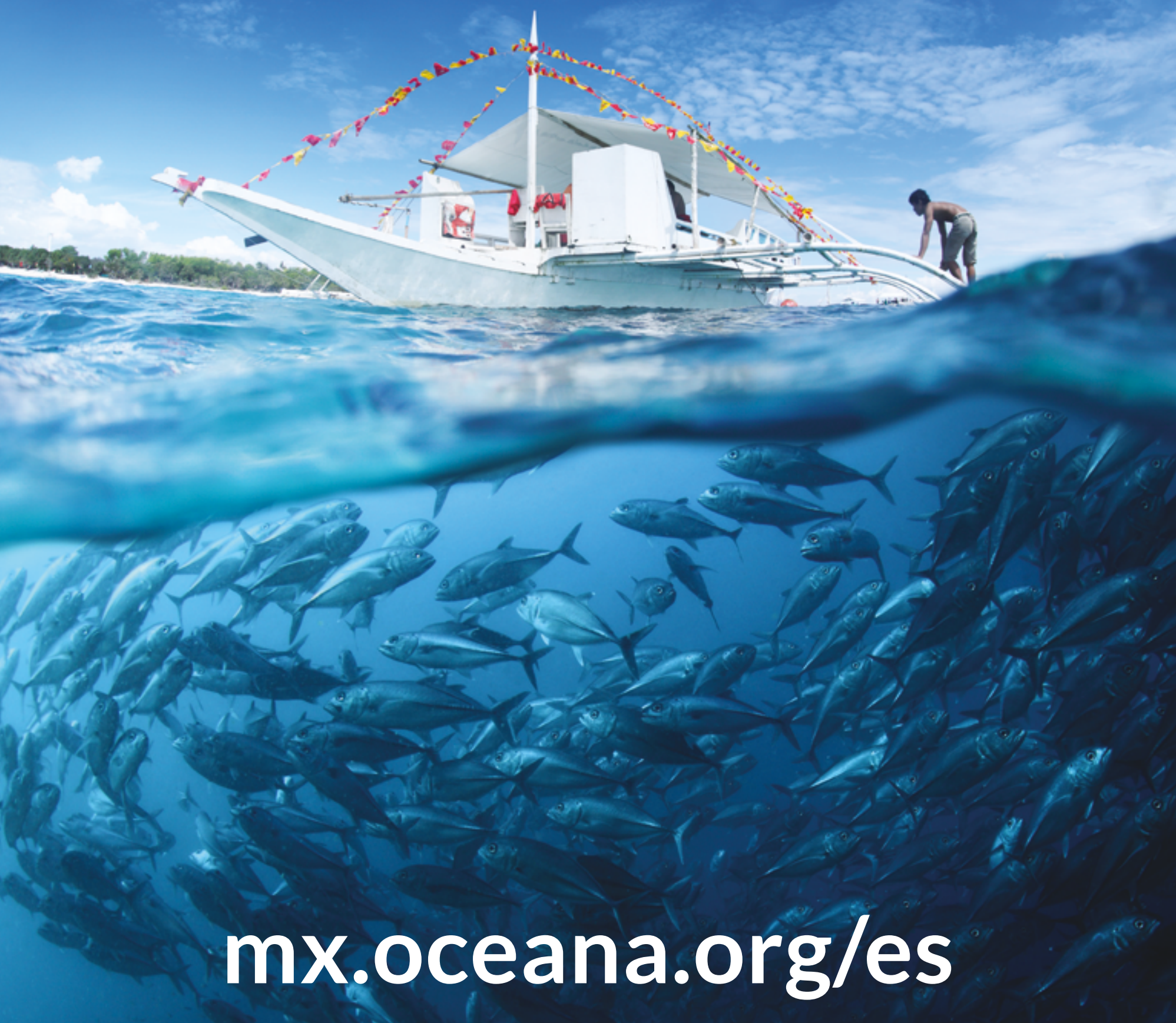

Consulta el reporte completo en: www.gatoxliebre.org

f @OceanaMexico

y @OceanaMexico

\section{OCEANA $\begin{gathered}\text { Protogeiendolos } \\ \text { Oceanos deliMundo }\end{gathered}$}

